\title{
Control of Glomerular Hypertension by Insulin Administration in Diabetic Rats
}

\author{
James W. Scholey and Timothy W. Meyer \\ Departments of Medicine, Palo Alto Veterans Administration Medical Center and Stanford University School of Medicine, \\ Stanford, California 94305
}

\section{Abstract}

Micropuncture studies were performed in Munich Wistar rats made diabetic with streptozotocin and in normal control rats. Diabetic rats received daily ultralente insulin to maintain moderate hyperglycemia $(\sim 300 \mathrm{mg} / \mathrm{dl})$. Group 1 diabetic rats studied after routine micropuncture preparation exhibited elevation of the single nephron glomerular filtration rate (SNGFR) due to increases in the glomerular transcapillary hydraulic pressure difference and glomerular plasma flow rate. In group 2 diabetic rats infusion of insulin to achieve acute blood glucose control normalized the glomerular transcapillary pressure gradient while increasing the glomerular ultrafiltration coefficient, so that SNGFR remained elevated. Persistent elevation of SNGFR despite normalization of the transcapillary pressure gradient was also observed in group 3 diabetic rats infused with insulin plus sufficient dextrose to maintain hyperglycemia. These studies indicate that glomerular capillary hypertension in diabetes is an acutely reversible consequence of insulin deficiency and not the result of renal hypertrophy.

\section{Introduction}

The early course of insulin dependent diabetes mellitus in humans and in rats is characterized by enlargement of the kidney and elevation of the glomerular filtration rate (1). Most micropuncture studies in diabetic rats have shown that the increase in glomerular filtration rate is due to increases in glomerular capillary plasma flow rate and hydraulic pressure (2-7). Marked elevation of the glomerular capillary pressure despite normal systemic blood pressure distinguishes diabetes from other experimental conditions in which glomerular hyperfiltration accompanies renal hypertrophy. Thus, when glomerular filtration rate and renal mass increase in parallel as a consequence of normal maturation, ingestion of a protein rich diet, or uninephrectomy, glomerular capillary pressure has been found to remain normal or to increase only moderately (8-13). Taken together, these findings suggest that glomerular capillary hypertension in diabetes is a consequence of insulin deficiency rather than a necessary result of renal hypertrophy. The current study was designed to assess whether acute insulin

Presented in part at the 19th Annual Meeting of the American Society of Nephrology, Washington, DC, December 1986.

Address reprint requests to Dr. Scholey, AKC 111R, Palo Alto Veterans Administration Medical Center, 3801 Miranda Avenue, Palo Alto, CA 94304.

Received for publication 20 February 1987 and in revised form 23 November 1988.

The Journal of Clinical Investigation, Inc.

Volume 83, April 1989, 1384-1389 replacement would lower glomerular capillary pressure in rats with established diabetic renal hypertrophy and hyperfiltration.

\section{Methods}

Micropuncture studies were performed in six groups of male Munich Wistar rats. 41 rats with initial body weights $218-278 \mathrm{~g}$ were made diabetic by tail vein injection of streptozotocin (STZ), ${ }^{1} 60 \mathrm{mg} / \mathrm{kg}$, under brevital anesthesia. Beginning $3 \mathrm{~d}$ after streptozotocin administration, rats received daily subcutaneous injections of $\sim 1 \mathrm{U}$ of heattreated ultralente insulin to maintain moderate hyperglycemia as previously described (14). Weekly measurements on blood obtained by tail clipping in 25 of the 41 diabetic rats established that this regimen maintained mean blood glucose $311 \pm 50 \mathrm{mg} / \mathrm{dl} \mathrm{SD}$.

Micropuncture protocol. Micropuncture studies were carried out 4-15 wk after STZ administration in diabetic rats and in a group of control rats of equal weight at the time of micropuncture study. Glucose was measured in blood obtained by tail clipping on the day of study and the diabetic rats were divided into five groups with similar blood glucose concentrations. Rats were then anesthetized with Inactin, $100 \mathrm{mg} / \mathrm{kg}$ i.p., and placed on a temperature regulated micropuncture table. A PE-50 tubing catheter was installed in the left femoral artery and used for subsequent blood sampling and estimation of mean arterial pressure $(\overline{\mathrm{AP}})$. $\overline{\mathrm{AP}}$ was continuously monitored with an electronic transducer connected to a direct writing recorder. After tracheostomy, PE catheters were installed in the right and left jugular veins for infusion of rat plasma and of saline, inulin, insulin, and dextrose. After insertion of the jugular catheters, plasma obtained from normal rats was infused in an amount equal to $1 \%$ body wt over 40 $\mathrm{min}$, followed by a reduction in infusion rate to $0.41 \mathrm{ml} / \mathrm{h}$ for the remainder of each experiment. Saline was infused at a rate of $1.2 \mathrm{ml} / \mathrm{h}$ throughout each experiment.

Group 1 diabetic rats received only plasma and saline infusions without additional insulin or glucose. After an equilibration period of 90-150 min following initiation of the plasma infusion, tritiated methoxy-inulin was added to the saline to obtain an infusion rate of 75-90 $\mu \mathrm{Ci} / \mathrm{h}$ after a loading dose of $\sim 40 \mu \mathrm{Ci}$. Micropuncture measurements were then carried out over two or three 25- to 45-min clearance periods. In each period, a $200-\mu 1$ arterial blood sample was obtained for determination of hematocrit (Hct) and plasma inulin, protein, and glucose concentrations. A renal vein blood sample was obtained with each arterial blood sample for determination of filtration fraction by comparison of arterial and renal vein inulin concentrations. Time averaged hydraulic pressures were measured in surface

1. Abbreviations used in this paper: $\mathrm{BG}_{\mathrm{mp}}$, blood glucose during micropuncture study; $\mathbf{B G}_{\text {pre }}$, blood glucose in awake rats before study; BW, body weight; $C_{A}$, afferent arteriolar plasma protein concentration; FF, filtration fraction; GFR, glomerular filtration rate; Hct, hematocrit; $K_{\mathrm{f}}$, glomerular capillary ultrafiltration coefficient; LKW, left kidney weight; MAP, mean arterial pressure; $P_{E}$, efferent arteriolar hydraulic pressure; $\overline{\mathrm{P}_{\mathrm{GC}}}$, mean glomerular capillary hydraulic pressure; $\mathbf{P}_{\mathrm{T}}$, proximal tubule hydraulic pressure; $\overline{\Delta \mathbf{P}}$, mean glomerular transcapillary hydraulic pressure difference; $\pi_{A}$ and $\pi_{E}$, afferent and efferent arteriolar colloid osmotic pressure; $Q_{\mathrm{A}}$, glomerular plasma flow rate; $R_{A}$ and $R_{E}$, afferent and efferent arteriolar resistance; $R_{T}$, total arteriolar resistance $\left(R_{A}+R_{E}\right)$; $S N G F R$, single nephron glomerular filtration rate; $\dot{V}$, urinary flow rate. 
glomerular capillaries, proximal tubules, and efferent arterioles with a continuous recording, Servonull micropipette transducer system (model V; Instrumentation for Physiology and Medicine, San Diego, CA). Hydraulic output from the servo-system was coupled to a second channel of the direct writing recorder by means of a pressure transducer. After pressure measurement, timed 4-min samples of tubule fluid were collected from surface convolutions of three to five nephrons for determination of single nephron glomerular filtration rate (SNGFR). A final arterial blood sample was obtained at the close of the study for determination of plasma potassium concentration.

Group 2 diabetic rats were studied in similar fashion except that an additional infusion of insulin (regular Iletin; Eli Lilly \& Co., Indianapolis, IN), $0.3 \mathrm{U} / \mathrm{ml}$ in normal saline, was begun along with the infusions of rat plasma and saline. This infusion was initiated at a rate of $0.29 \mathrm{U} / \mathrm{h}$. Glucose concentrations were determined on $15-\mu \mathrm{l}$ blood samples at $\sim 20$-min intervals and the insulin infusion rate progressively adjusted downward as blood glucose concentrations fell. A period extending $\sim 90 \mathrm{~min}$ after initiation of the insulin infusion was required to reduce blood glucose concentrations below $140 \mathrm{mg} / \mathrm{dl}$. Insulin infusion rates of 0.00 to $0.08 \mathrm{U} / \mathrm{h}$ served to maintain individual blood glucose readings in the range $75-140 \mathrm{mg} / \mathrm{dl}$ during micropuncture measurements, which were initiated at the same interval after surgical preparation as in group 1.

Group 3 diabetic rats also received an infusion of insulin along with rat plasma and normal saline. In this group, the insulin infusion rate was maintained at $0.29 \mathrm{U} / \mathrm{h}$ throughout the study. In addition, an infusion of $50 \%$ dextrose was begun $20 \mathrm{~min}$ after initiation of insulin infusion. The dextrose infusion rate was adjusted between $0.69 \mathrm{ml} / \mathrm{h}$ and $0.93 \mathrm{ml} / \mathrm{h}$ to maintain blood glucose concentrations during micropuncture study between 240 and $320 \mathrm{mg} / \mathrm{dl}$, values similar to those observed in group 1 diabetic rats receiving no insulin.

Group 4 consisted of nine normal male Munich Wistar rats whose weights were matched to those of the diabetic rats at the time of micropuncture study. Plasma and saline were infused as in group 1 diabetic rats, and micropuncture measurements were performed at a similar interval after surgical preparation as in the other groups.

Groups 5 and 6 each consisted of six diabetic rats prepared for micropuncture study exactly as described for groups 1 and 2, respectively. Studies in these rats served to compare values for SNGFR obtained by puncture of proximal and distal nephrons. Proximal and distal nephron segments were located by injection of small amounts of FD\&C green dye ( $1 \%$ in saline) through a pipette with a tip of $\sim 5 \mu \mathrm{m}$ OD. Timed 4-min tubule fluid samples were then collected from three to five distal nephron segments and three to five proximal nephron segments. These collections were carried out over two 30- to 50-min collection periods. In each period, a $200-\mu \mathrm{l}$ blood sample was obtained for determination of Hct and plasma inulin, protein glucose, sodium, and potassium concentrations. An arterial blood sample was obtained at the close of each study for determination of arterial blood pH, $\mathrm{PCO}_{2}$, and bicarbonate concentration.

Analytical. Blood glucose concentrations were determined with reagent strips and a Glucometer (Miles Laboratories, Elkhart, IN). Arterial plasma protein concentration $\left(C_{A}\right)$ was determined by refractometry and plasma potassium concentration by flame photometry. Radioinulin content of plasma, urine, and tubule fluid samples was assessed by liquid phase scintillation counting. Plasma sodium and potassium concentrations were determined by flame photometry. Arterial blood gas analysis was performed on capillary samples with a Corning $168 \mathrm{pH} / \mathrm{blood}$ gas analyzer (Corning Medical and Scientific, Medfield, MA).

Calculations and statistics. Efferent arteriolar total plasma protein concentration $\left(C_{\mathrm{E}}\right)$ was estimated from the relation

$\mathrm{C}_{\mathrm{E}}=\frac{\mathrm{C}_{\mathrm{A}}}{1-\mathrm{FF}}$

Oncotic pressure $(\pi)$ of efferent and afferent arteriolar plasma was estimated from total protein concentration (C) as

$\pi=1.629 \mathrm{C}+0.294 \mathrm{C}^{2}$
A standard mathematical model was used to derive the glomerular capillary ultrafiltration coefficient $\left(K_{\mathrm{f}}\right)$ and single afferent and efferent arteriolar resistances from oncotic pressure values and from measured parameters (15). The statistical significance of differences among values of individual parameters in the four experimental groups was evaluated by the analysis of variance. The Newman-Keuls multiple range test was used to assess the significance of differences between individual group means (six comparisons) with significance defined as $P<0.05$. Values are expressed as mean \pm 1 SE unless noted otherwise.

\section{Results}

Mean values for body weight, blood glucose, mean arterial pressure under anesthesia, GFR, kidney weight, SNGFR, and the pressures flows and resistances governing glomerular ultrafiltration for groups 1-4 are summarized in Table I. Body weight was equivalent among the different groups. By design, blood glucose levels in unanesthetized rats immediately before study $\left(\mathrm{BG}_{\mathrm{pre}}\right)$ were equivalent in the three diabetic groups and markedly elevated above the level of $88 \pm 5 \mathrm{mg} / \mathrm{dl}$ observed in normal group 4 rats. With anesthesia and surgical preparation, mean blood glucose level during micropuncture study $\left(\mathrm{BG}_{\mathrm{mp}}\right)$ was reduced slightly to $260 \pm 9 \mathrm{mg} / \mathrm{dl}$ in group 1 diabetic rats which received no additional insulin. In contrast, insulin infusion markedly reduced blood glucose levels during micropuncture study in group 2 diabetic rats. Insulin infusion in this group was regulated so that no individual glucose value fell below $75 \mathrm{mg} / \mathrm{dl}$. The mean value for $\mathrm{BG}_{\mathrm{mp}}$ in group $2,116 \pm 3$ $\mathrm{mg} / \mathrm{dl}$, thus remained significantly though only slightly above the value observed in normal rats. In group 3 diabetic rats infusion of dextrose along with insulin served to maintain $\mathrm{BG}_{\mathrm{mp}}$ at $275 \pm 9 \mathrm{mg} / \mathrm{dl}$, a value similar to that observed in group 1.

Infusion of insulin during micropuncture study had no effect on mean arterial pressure $(\overline{\mathrm{AP}})$ or on hematocrit $(\mathrm{Hct})$. Values for these parameters were similar in the three groups of diabetic rats and in group 4 control rats. Values for arterial plasma protein concentration $\left(C_{A}\right)$ were similar in groups 1,2 , and 4. A slight but significant reduction in $C_{A}$ in group 3 presumably reflected mild ECF volume expansion in this group. Group 3 rats received an average of $3.0 \mathrm{ml}$ of saline (with insulin) and $1.7 \mathrm{ml}$ of water (as 50\% dextrose) in addition to the $1.2 \mathrm{ml} / \mathrm{h}$ saline infusion routinely provided with micropuncture preparation, while group 2 rats received an average of $1.3 \mathrm{ml}$ of saline (with insulin) in addition to the $1.2 \mathrm{ml} / \mathrm{h}$ saline infusion routinely provided with micropuncture preparation.

In accord with previous reports (2-7), whole kidney GFR was elevated above normal in group 1 diabetic rats which were maintained moderately hyperglycemic for 4-9 wk and then subjected to micropuncture study. GFR was significantly reduced but still remained above normal when insulin was infused alone in group 2 and along with added dextrose to maintain hyperglycemia in group 3 . Values for filtration fraction (FF) were not different among the four groups, so that values for renal plasma flow closely paralleled values for GFR.

Elevation of whole kidney GFR reflected single nephron hyperfiltration in each of the diabetic groups. The hemodynamic alterations responsible for single nephron hyperfiltration in group 1 were similar to those previously described in moderately hyperglycemic diabetic rats $(2-7)$. The glomerular transcapillary hydraulic pressure gradient $(\overline{\Delta \mathrm{P}})$, was elevated to $49 \pm 1 \mathrm{mmHg}$, a value $8 \mathrm{mmHg}$ greater than that observed in 
Table I. Summary of Renal Cortical Microcirculation Studies (Groups 1-4)

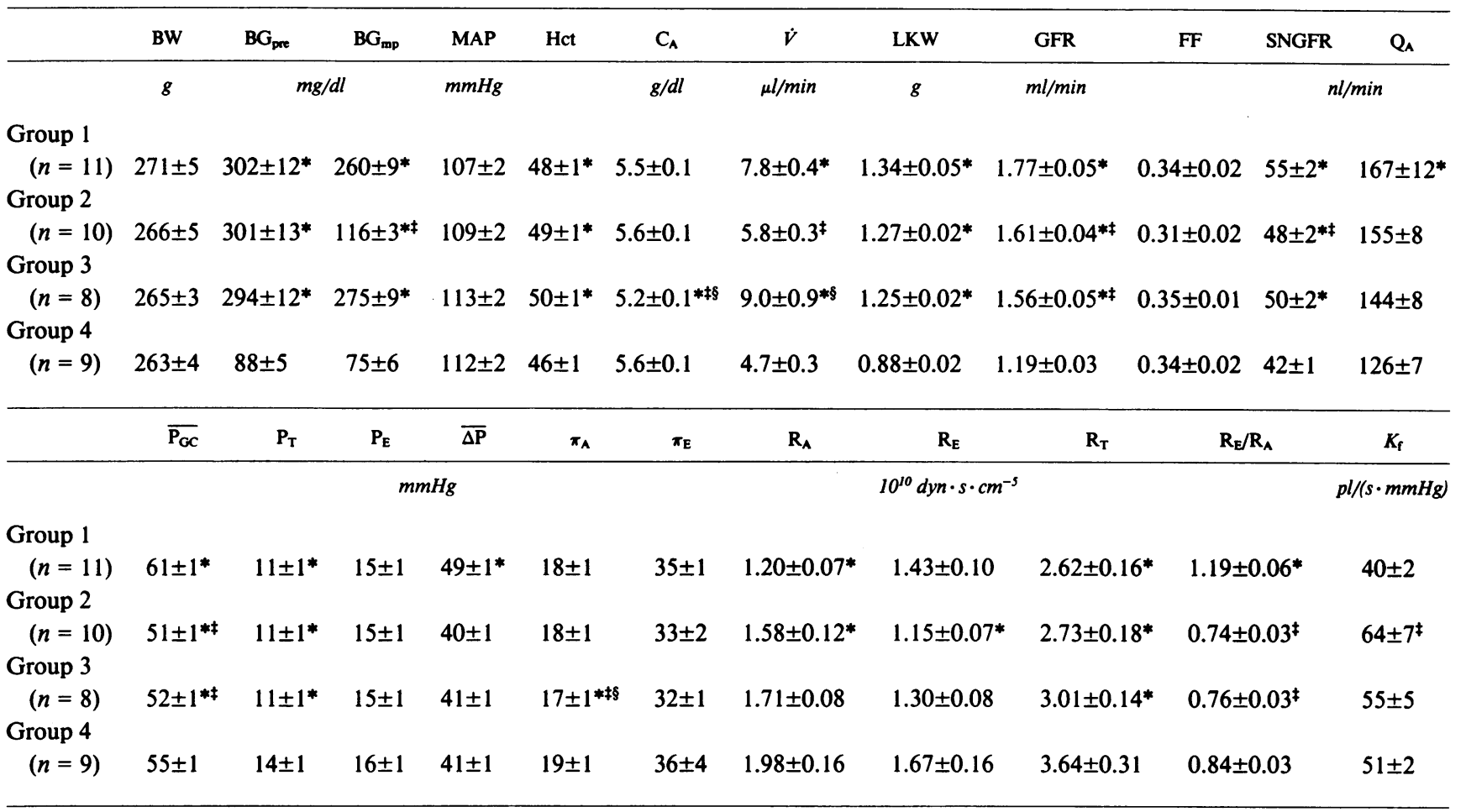

Mean values \pm SEM. Abbreviations: $\mathrm{BW}$, body weight; $\mathrm{BG}_{\mathrm{pre}}$, blood glucose in awake rats before study; $\mathrm{BG}_{\mathrm{mp}}$, blood glucose during micropuncture study; MAP, mean arterial pressure; Hct, hematocrit; $C_{A}$, afferent arteriolar plasma protein concentration; $\dot{V}$, urinary flow rate; LKW, left kidney weight; GFR, glomerular filtration rate; FF, filtration fraction; SNGFR, single nephron glomerular filtration rate; $Q_{\mathrm{A}}$, glomerular plasma flow rate; $P_{G C}$, mean glomerular capillary hydraulic pressure; $P_{T}$, proximal tubule hydraulic pressure; $P_{E}$, efferent arteriolar hydraulic pressure; $\Delta \mathrm{P}$, mean glomerular transcapillary hydraulic pressure difference; $\pi_{A}$ and $\pi_{E}$, afferent and efferent arteriolar colloid osmotic pressure; $R_{A}$ and $R_{E}$, afferent and efferent arteriolar resistance; $R_{T}$, total arteriolar resistance $\left(R_{A}+R_{E}\right) ; K_{f}$, glomerular capillary ultrafiltration coefficient. * Values for groups $1,2,3$ significantly different from group $4, P<0.05$. ${ }^{\ddagger}$ Groups 2 and 3 different from group $1, P<0.05$. ${ }^{\S}$ Group 3 different from group $2, P<0.05$.

normal group 4 rats. This high average value for $\overline{\Delta \mathrm{P}}$ in group 1 resulted largely from elevation of the mean glomerular capillary hydraulic pressure, $\overline{\mathrm{P}_{\mathrm{GC}}}$, which averaged $61 \pm 1 \mathrm{mmHg}$. The increase in $\overline{\Delta \mathrm{P}}$ led to a marked increase in mean glomerular ultrafiltration pressure, as afferent oncotic pressure $\pi_{A}$ was no different than in normal rats, and glomerular plasma flow rate, $Q_{\mathrm{A}}$, was increased to $167 \pm 12 \mathrm{nl} / \mathrm{min}$. Of note, despite prominent renal hypertrophy, the value derived for the glomerular ultrafiltration coefficient $\left(K_{f}\right)$ in diabetic rats, $40 \pm 2$ $\mathrm{pl} /(\mathrm{s} \cdot \mathrm{mmHg})$, was no greater than the value of $51 \pm 2$ $\mathrm{pl} /(\mathrm{s} \cdot \mathrm{mmHg})$ found in normal rats.

Elevation of $\overline{\mathrm{P}_{\mathrm{GC}}}$ and $\overline{\Delta \mathrm{P}}$ in group 1 diabetic rats reflected a relative increase in efferent arteriolar resistance, $R_{E}$. While increased plasma flow in the enlarged diabetic kidneys was due to a decline in total arteriolar resistance, $R_{T}$, from $3.6 \pm 0.3$ to $2.6 \pm 0.2 \times 10^{10} \mathrm{dyn} \cdot \mathrm{s} \cdot \mathrm{cm}^{-5}$, efferent resistance remained unchanged, so that the ratio of efferent resistance to afferent resistance, $R_{E} / R_{A}$, was significantly increased. Acute infusion of insulin over the course of micropuncture study had a dramatic effect on the pattern of intrarenal vascular resistance in group 2 diabetic rats. Infusion of sufficient insulin to achieve acute blood glucose control resulted in a fall in efferent resistance with a return in the ratio $R_{E} / R_{A}$ to $0.74 \pm 0.03$, a value similar to that observed in normal rats. Reduction of the proportion of efferent to afferent resistance reduced $\overline{P_{G C}}$ to $51 \pm 1$ $\mathrm{mmHg}$ and $\overline{\Delta \mathrm{P}}$ to $39 \pm 1 \mathrm{mmHg}$, values similar to those seen in normal rats. While $\overline{\Delta \mathrm{P}}$ was returned to normal by acute insulin infusion in group 2 rats, SNGFR and whole kidney GFR remained elevated. Continued hyperfiltration despite reduction in ultrafiltration pressure during insulin infusion reflected an increase in $K_{\mathrm{f}}$ to $64 \pm 7 \mathrm{pl} /(\mathrm{s} \cdot \mathrm{mmHg})$, significantly above the level seen in group 1 diabetic rats.

Values for the determinants of glomerular filtration in group 3 rats were closely similar to those in group 2 rats. Thus the acute effect of insulin infusion on intrarenal vascular resistance was still observed when dextrose was infused in order to maintain blood glucose at the level observed in group 1. With infusion of insulin and dextrose, the ratio $R_{E} / R_{A}$ in group 3 was reduced to $0.76 \pm 0.03$, a value similar to that observed in both group 2 diabetic rats receiving insulin alone and in group 4 normal control rats. Since arterial pressure was not changed by insulin and dextrose infusion, normalization of the proportion of efferent to afferent resistance again led to reduction of $\overline{\mathrm{P}_{\mathrm{GC}}}$ and $\overline{\Delta \mathrm{P}}$. Despite reduction in $\overline{\mathrm{AP}}$, SNGFR decreased only slightly to $50 \pm 1 \mathrm{nl} / \mathrm{min}$ as $K_{\mathrm{f}}$ increased to $55 \pm 5 \mathrm{pl}(\mathrm{s} \cdot \mathrm{mmHg})$, a value again greater than that seen in group 1 diabetic rats.

The calculation of two of the determinants of surface nephron filtration rate in the current study, $Q_{\mathrm{A}}$ and $K_{\mathrm{f}}$, has been based on the assumption that surface nephron filtration fraction is similar to whole kidney filtration fraction. This assumption has been validated for moderately hyperglycemic diabetic rats $(16)$ and for normal rats $(17,18)$ but remains 
unproven for rats acutely infused with insulin. It would require, however, a marked fall in surface nephron filtration fraction occasioned by a vasodilator effect of insulin restricted to the surface of the kidney to invalidate the conclusion that $K_{\mathrm{f}}$ rose while $\Delta \mathrm{P}$ declined during insulin administration in the current study.

Results of studies in groups 5 and 6 diabetic rats are summarized in Table II. By design, values for blood glucose were similar to those observed in groups 1 and 2, respectively. As in group 2, insulin infusion in group 6 did not cause significant changes in mean arterial pressure, hematocrit, or plasma protein concentration. Insulin infusion also had no significant effect on plasma sodium or potassium concentration. As described in previous reports $(7,16)$, moderately hyperglycemic diabetic rats were not acidemic and systemic $\mathrm{pH}$ was not significantly altered by insulin infusion in group 6 . Values for single nephron filtration rate obtained by distal sampling (SNGFR $_{d}$ ) were less than those obtained by proximal sampling $\left(\mathrm{SNGFR}_{\mathrm{p}}\right.$ ) in both groups 5 and 6, and the proportion of this difference was similar in the two groups.

\section{Discussion}

Insulin dependent diabetes in humans and in rats is characterized by increases in glomerular filtration rate and renal mass which precede development of proteinuric renal disease $(1,4)$. In diabetic rats, the increase in glomerular filtration rate has been shown to result from increases in $Q_{\mathrm{A}}$ and in $\overline{\mathrm{P}_{\mathrm{GC}}}$ and $\overline{\Delta \mathrm{P}}$ (2-7). Results in group 1 diabetic rats in the current study confirm these findings. Like previous studies, they show further that because mean arterial pressure is normal in diabetic rats, the increase in $Q_{\mathrm{A}}$ reflects a decrease in total renal vascular resistance, while the increase in $\overline{\mathrm{P}_{\mathrm{GC}}}$ reflects an increase in the proportion of efferent arteriolar resistance to afferent arteriolar resistance (5).

The current study assessed the dependence of the altered pattern of arteriolar resistance within the diabetic kidney on insulin deficiency. In group 2 diabetic rats, provision of sufficient insulin to return blood glucose near to normal levels restored the normal proportion of efferent to afferent arteriolar resistance. Since blood pressure was unaltered, glomerular capillary pressure was normalized when the pattern of vascular resistance in the diabetic kidney was corrected by acute insulin administration.

Despite normalization of glomerular capillary pressure, glomerular filtration rate was only slightly reduced and remained significantly above normal in diabetic rats infused with insulin over 2 to $4 \mathrm{~h}$. A similar effect of acute insulin administration on GFR has been observed in diabetic humans by Christiansen et al. (19). In their study, GFR was reduced but remained significantly above normal in type $I$ diabetic patients whose blood glucose was normalized over $2 \mathrm{~h}$. The glomerular hemodynamic changes responsible for this effect of insulin are revealed in the current study. First, glomerular capillary plasma flow in the hypertrophied diabetic kidney remained elevated while the proportion of efferent to afferent resistance was normalized by insulin administration. Second, the glomerular capillary ultrafiltration coefficient, $K_{\mathrm{f}}$, was increased while $\overline{\Delta \mathrm{P}}$ was reduced.

The ability of insulin to acutely increase $K_{\mathrm{f}}$ in diabetic rats is a remarkable finding of the current study. Morphologic studies have shown that hyperfiltration in diabetic humans and rats is associated with enlargement of glomeruli and an increase in the glomerular capillary surface area available for plasma ultrafiltration (20-22). Functional studies, however, have revealed that $K_{\mathrm{f}}$ remains normal or is slightly reduced in diabetic rats (2-6). It has been suggested that reduction of $K_{\mathrm{f}}$ despite glomerular enlargement reflects an early pathologic change in the glomerular capillary wall leading to decreased hydraulic permeability (5). In the current study, acute insulin administration in group 2 diabetic rats increased $K_{\mathrm{f}}$ to a value significantly greater than that observed in group 1 diabetic rats receiving no insulin and numerically greater than that observed in control rats. This finding indicates that restriction of $K_{\mathrm{f}}$ in early diabetes does not reflect glomerular pathology but is rather, like the relative increase in efferent to afferent arteriolar resistance, a functional consequence of insulin deficiency.

The current study suggests that glomerular hyperfiltration in early diabetes may be considered to have a structural component, related to renal hypertrophy, and a functional component, including changes in arteriolar resistance and in $K_{\mathrm{f}}$ which are acutely reversible by insulin administration. With sufficient insulin to normalize blood glucose, GFR in the hypertrophied kidneys of group 2 rats remained above normal. Elevation of GFR in this setting was due to elevation of $Q_{\mathrm{A}}$ in the enlarged kidneys and to elevation of $K_{\mathrm{f}}$ in enlarged glomeruli while $\overline{\Delta \mathrm{P}}$ was normal. In insulinopenic group 1 rats, a superimposed increase in $\overline{\Delta \mathrm{P}}$ caused a further small increase in GFR despite a reduction in $K_{\mathrm{f}}$. Results obtained when kidney growth is induced by other means provide a noteworthy comparison to these findings. In rats subjected to uninephrectomy increases in kidney weight and glomerular filtration rate are comparable to those observed in diabetes but increases in $\overline{\Delta \mathbf{P}}$ have, on average, been found to be of lesser magnitude (11-13). When renal growth is induced by protein feeding or occurs in the normal course of maturation, increases in GFR have been shown to result from increases in $Q_{\mathrm{A}}$ and $K_{\mathrm{f}}$ without any increase in $\overline{\Delta \mathrm{P}}(8-10)$. Together with the findings of the

Table II. Summary of Microcirculation Studies (Groups 5 and 6)

\begin{tabular}{|c|c|c|c|c|c|c|c|c|c|c|c|c|c|c|}
\hline & BW & $\mathrm{BG}_{\mathrm{pre}}$ & $B G_{m p}$ & MAP & Het & $\mathrm{C}_{\boldsymbol{A}}$ & {$\left[\mathrm{Na}^{+}\right]$} & {$\left[\mathrm{K}^{+}\right]$} & $\mathrm{pH}$ & {$\left[\mathrm{HCO}_{3}^{-}\right]$} & $\mathrm{PCO}_{2}$ & GFR & SNGFR $_{p}$ & SNGFR $_{d}$ \\
\hline & $g$ & \multicolumn{2}{|c|}{$m g / d l$} & $m m H g$ & & $g / d l$ & \multicolumn{2}{|c|}{ meq/liter } & & meq/liter & $m m H g$ & $\mathrm{ml} / \mathrm{min}$ & \multicolumn{2}{|c|}{$n l / \min$} \\
\hline $\begin{array}{l}\text { Group 5 } \\
\quad(n=6)\end{array}$ & $288 \pm 7$ & $291 \pm 18$ & $276 \pm 7$ & $108 \pm 3$ & $45 \pm 1$ & $5.4 \pm 0.1$ & $142 \pm 1$ & $3.8 \pm 0.1$ & $7.38 \pm 0.01$ & $26 \pm 1$ & $43 \pm 1$ & $1.73 \pm 0.08$ & $51 \pm 2$ & $41 \pm 2$ \\
\hline $\begin{array}{l}\text { Group } 6 \\
\quad(n=6)\end{array}$ & $290 \pm 7$ & $281 \pm 11$ & $114 \pm 5^{*}$ & $112 \pm 2$ & $46 \pm 1$ & $5.3 \pm 0.1$ & $144 \pm 2$ & $3.6 \pm 0.1$ & $7.41 \pm 0.01$ & $27 \pm 1$ & $42 \pm 1$ & $1.52 \pm 0.06$ & $54 \pm 3$ & $42 \pm 4$ \\
\hline
\end{tabular}

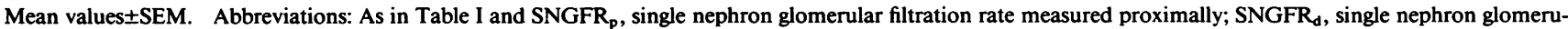
lar filtration rate measured distally; $\left[\mathrm{Na}^{+}\right]$, plasma sodium concentration; $\left[\mathrm{K}^{+}\right]$, plasma potassium concentration. $* P<0.05$ group 5 vs. group 6 . 
current study, these results suggest that glomerular capillary hypertension in diabetes should not be viewed as a natural consequence of renal hypertrophy, but rather as a functional consequence of the diabetic state.

The mechanism by which acute insulin administration alters renal arteriolar resistances and $K_{\mathrm{f}}$ in diabetes remains to be identified. Results of the current study show that these effects of insulin do not depend on reduction of the blood glucose level. Thus $\overline{\Delta \mathbf{P}}$ was normalized while glomerular filtration rate remained elevated in group 3 rats given insulin plus sufficient dextrose to maintain hyperglycemia. This result is consistent with the finding of Blantz et al. (23) that elevation of blood glucose by itself does not alter $\overline{\mathrm{P}_{\mathrm{GC}}}$ in normal rats. Studies in group 3 rats further indicate that reduction in $\overline{\mathrm{P}_{\mathrm{GC}}}$ accompanying insulin administration was not caused by ECF volume contraction. Since hyperglycemia was maintained in these animals, insulin administration should have caused no shift of ECF fluid into the cellular compartment. Moreover, animals in group 3 received more saline (with insulin) than animals in the other groups and exhibited a slightly lower value for $C_{\mathrm{A}}$. Yet $\overline{\Delta \mathbf{P}}$ was reduced as effectively by insulin infusion in group 3 as it was in group 2 .

It has been suggested that tubuloglomerular feedback may be altered by hyperglycemia (23-25). The finding that SNGFR values obtained by distal puncture were lower than SNGFR values obtained by proximal puncture in group 5 rats indicates that tubuloglomerular feedback remains operative in diabetic rats. This finding is consistent with results of a recent study by Seney et al. (25) showing that the differences in SNGFR values obtained by proximal and distal puncture are similar in diabetic and in normal rats. The finding that the difference in SNGFR values obtained by proximal and distal puncture was not effected by insulin indicates that use of proximal puncture did not cause erroneous characterization of insulin's glomerular hemodynamic effects in the present study.

The glomerular hemodynamic effects of insulin observed in the present study may reflect a direct effect of insulin on glomerular function. Insulin receptors have been identified in isolated rat glomeruli, and occupancy of these receptors could directly alter $K_{\mathrm{f}}(26)$. Alternatively, the glomerular hemodynamic effects of insulin deficiency could reflect altered production of vasoactive hormones within the kidney. The pattern of an increase in the proportion of efferent to afferent arteriolar resistance along with reduction in $K_{\mathrm{f}}$ seen in diabetes is strikingly similar to that observed in rats acutely infused with angiotensin II $(27,28)$. Furthermore, recent studies have shown that chronic treatment with the angiotensin II converting enzyme inhibitor enalapril normalizes $\overline{\mathrm{P}_{\mathrm{GC}}}$ while maintaining glomerular hyperfiltration in diabetic rats (4). Thus, while circulating renin levels in moderately hyperglycemic rats have been found to be normal, it remains possible that intrarenal angiotensin II activity in these rats is increased (29).

Other studies suggest that altered renal prostanoid synthesis contributes to glomerular hyperfiltration and glomerular capillary hypertension in diabetes (30-32). Most of these studies have explored the hypothesis that increased production of vasodilator prostaglandins elevates plasma flow and glomerular filtration rates in the diabetic kidney. So far, however, attempts to lower GFR by inhibiting prostaglandin synthesis in both diabetic humans and rats have yielded conflicting results $(5,31,33,34)$. Recently, Stoff et al. (32) proposed an alternate mechanism by which altered prostaglandin production may affect glomerular hemodynamic function in diabetes. Their findings in cultured mesangial cells and in the isolated perfused kidney suggest that insulin deficiency prevents the generation of vasodilator prostaglandins which normally oppose angiotensin II mediated renal vasoconstriction and mesangial cell contraction. As previously noted, potentiation of these effects of angiotensin II could account for the pattern of increased efferent resistance and restricted $K_{\mathrm{f}}$ observed in the diabetic kidney. Clearly, further functional studies are needed to define the role played by angiotensin II and other vasoactive hormones in altering glomerular function in diabetes. The current study establishes that the increased proportion of efferent to afferent resistance and restriction of $K_{\mathrm{f}}$ seen in diabetes are acutely reversible consequences of insulin deficiency and not the result of structural changes associated with renal hypertrophy.

\section{Acknowledgments}

We are grateful to Brittmarie Anderssen for expert technical assistance. Supported by grants from the Juvenile Diabetes Foundation and the National Institutes of Health (R23 DK-357341). Dr. Scholey is supported by a research fellowship from the Medical Research Council of Canada.

\section{References}

1. Hostetter, T. H., H. G. Rennke, and B. M. Brenner. 1982. The case for intrarenal hypertension in the initiation and progression of diabetic and other glomerulopathies. Am. J. Med. 72:375-380.

2. Hostetter, T. H., J. L. Troy, and B. M. Brenner. 1981. Glomerular hemodynamics in experimental diabetes mellitus. Kidney Int. 19:410-415.

3. Azar, S. 1978. Increased glomerular capillary pressure in pancreatectomized rats with short-term diabetes. Clin. Res. 26:725. (Abstr.)

4. Zatz, R., B. R. Dunn, T. W. Meyer, S. Anderson, H. G. Rennke, and B. M. Brenner. 1986. Prevention of diabetic glomerulopathy by pharmacological amelioration of glomerular capillary hypertension. $J$. Clin. Invest. 77:1925-1930.

5. Jensen, P. K., K. Steven, H. Blaehr, J. S. Christiansen, and H.-H. Parving. 1986. Effects of indomethacin on glomerular hemodynamics in experimental diabetes. Kidney Int. 29:490-495.

6. Jensen, P. K., J. S. Christiansen, K. Steven, and H.-H. Parving. 1987. Strict metabolic control and renal function in the streptozotocin diabetic rat. Kidney Int. 31:47-51.

7. Bank, N., R. Klose, H. S. Aynedjian, D. Nguyen, and L. B. Sablay. 1987. Evidence against increased glomerular pressure initiating diabetic nephropathy. Kidney Int. 31:898-905.

8. Tucker, B. J., and R. C. Blantz. 1977. Factors determining superficial nephron filtration in the mature, growing rat. Am. J. Physiol. 232:F97-F104.

9. Ichikawa, I., D. A. Maddox, and B. M. Brenner. 1979. Maturational development of glomerular ultrafiltration in the rat. Am. J. Physiol. 236:F465-F471.

10. Ichikawa, I., M. L. Purkerson, S. Klahr, J. L. Troy, M. Martinez-Maldonado, and B. M. Brenner. 1980. Mechanism of reduced glomerular filtration rate in chronic malnutrition. J. Clin. Invest. 65:982-988.

11. Deen, W. M., D. A. Maddox, C. R. Robertson, and B. M. Brenner. 1974. Dynamics of glomerular ultrafiltration in the rat. VII. Response to reduced renal mass. Am. J. Physiol. 227:556-562.

12. Finn, W. F. 1982. Compensatory renal hypertrophy in Sprague-Dawley rats: glomerular ultrafiltration dynamics. Renal Physiol. 5:224-234.

13. Dworkin, L. D., T. H. Hostetter, H. G. Rennke, and B. M. 
Brenner. 1984. Hemodynamic basis for glomerular injury in rats with deoxycorticosterone-salt hypertension. J. Clin. Invest. 73:1448-1461.

14. Rasch, R. 1979. Control of blood glucose levels in the streptozotocin diabetic rat using a long-acting heat treated insulin. Diabetologia. 16:185-190.

15. Deen, W. M., J. L. Troy, C. R. Robertson, and B. M. Brenner. 1973. Dynamics of glomerular ultrafiltration in the rat. IV. Determination of the ultrafiltration coefficient. J. Clin. Invest. 52:1500-1508.

16. Michels, L. D., M. Davidman, and W. F. Keane. 1981. Determinants of glomerular filtration and plasma flow in experimental diabetic rats. J. Lab. Clin. Med. 98:869-885.

17. Dilley, J. R., A. Corradi, and W. J. Arendshorst. 1983. Glomerular ultrafiltration dynamics during increased renal venous pressure. Am. J. Physiol. 244:F650-F658.

18. Baylis, C. 1982. Glomerular ultrafiltration in the pseudopregnant rat. J. Clin. Invest. 234:F300-F305.

19. Christiansen, J. S., M. Frandsen, and H.-H. Parving. 1981. The effect of intravenous insulin infusion on kidney function in insulindependent diabetes mellitus. Diabetologia. 20:199-204.

20. Østerby, R., and H. J. G. Gundersen. 1975. Glomerular size and structure in diabetes mellitus. I. Early abnormalities. Diabetologia. 11:225-229.

21. Hirose, K., R. Østerby, M. Nozawa, and H. J. G. Gundersen. 1982. Development of glomerular lesions in experimental long-term diabetes in the rat. Kidney Int. 21:689-695.

22. Hirose, K., H. Tsuchida, R. Østerby, and H. J. G. Gundersen. 1980. A strong correlation between glomerular filtration rate and filtration surface in diabetic kidney hyperfunction. Lab. Invest. 43:434437.

23. Blantz, R. C., B. J. Tucker, L. Gushwa, and O. W. Peterson. 1983. Mechanism of diuresis following acute modest hyperglycemia in the rat. Am. J. Physiol. 244:F185-F194.

24. Woods, L. L., H. L. Mizelle, and J. E. Hall. 1987. Control of renal hemodynamics in hyperglycemia: possible role of tubuloglomerular feedback. Am. J. Physiol. 252:F65-F73.
25. Seney, F. D., and R. Salmond. 1988. Tubuloglomerular feedback in diabetic rats. Kidney Int. 33:412. (Abstr.)

26. Kurokawa, K., F. J. Silverblatt, K. L. Klein, M.-S. Wang, and R. J. Lerner. 1979. Binding of ${ }^{125} \mathrm{I}$-Insulin to the isolated glomeruli of rat kidney. J. Clin. Invest. 64:1357-1364.

27. Blantz, R. C., K. S. Konnen, and B. J. Tucker. 1976. Angiotensin II effects upon the glomerular microcirculation and ultrafiltration coefficient in the rat. J. Clin. Invest. 57:419-434.

28. Ichikawa, I., J. F. Miele, and B. M. Brenner. 1979. Reversal of renal cortical actions of angiotensin II by verapamil and manganese. Kidney Int. 16:137-147.

29. Ballerman, B. J., K. L. Skorecki, and B. M. Brenner. 1984. Reduced glomerular angiotensin II density in early untreated diabetes mellitus in the rat. Am. J. Physiol. 247:F110-F116.

30. Schambelan, M., S. Blake, J. Sraer, M. Bens, M.-P. Nivez, and F. Wahbe. 1985 . Increased prostaglandin production by glomeruli isolated from rats with streptozotocin-induced diabetes mellitus. J. Clin. Invest. 75:404-412.

31. Esmatjes, E., M. R. Fernandez, I. Halperin, J. Camps, J. Gaya, V. Arroyo, F. Rivera, and D. Figuerola. 1985. Renal hemodynamic abnormalities in patients with short term insulin-dependent diabetes mellitus: role of renal prostaglandins. J. Clin. Endocrinol. Metab. 60:1231-1236.

32. Stoff, J. S., D. R. Leone, and A. Cohen. 1987. Insulin-angiotensin II interaction and dependence on prostaglandin biosynthesis. Kidney Int. 31:288. (Abstr.)

33. Christiansen, J. S., B. Feldt-Rasmussen, and H.-H. Parving. 1985. Short-term inhibition of prostaglandin synthesis has no effect on the elevated glomerular filtration rate of early insulin-dependent diabetes. Diabetic Med. 2:17-20.

34. Bank, N., M. A. G. Lahorra, H. S. Aynedjian, and D. Schlondorff. 1987. Role of vasoactive hormones in hyperfiltration of diabetes. Kidney Int. 31:259. (Abstr.) 